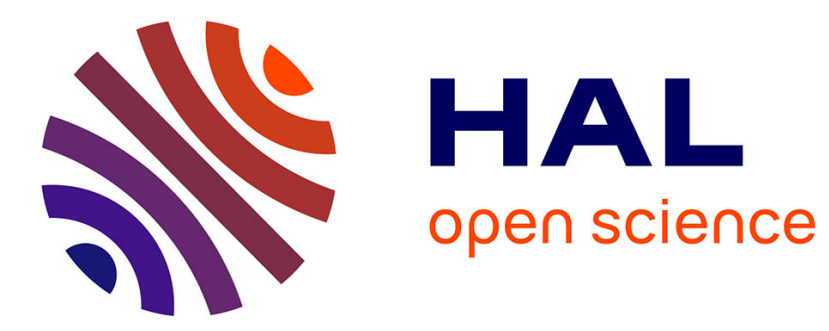

\title{
White light emission from Sm-doped YAG ceramic controlled by the excitation wavelengths
}

Hanan Ali, P. Masschelein, S. Bruyere, P. Pigeat, A. Dauscher, H. Rinnert, David Horwat, Mohamed Atta Khedr, Alaa Giba

\section{- To cite this version:}

Hanan Ali, P. Masschelein, S. Bruyere, P. Pigeat, A. Dauscher, et al.. White light emission from Sm-doped YAG ceramic controlled by the excitation wavelengths. Optics and Laser Technology, 2021, 142, pp.107223. 10.1016/j.optlastec.2021.107223 . hal-03278415

\section{HAL Id: hal-03278415 https://hal.science/hal-03278415}

Submitted on 8 Jul 2021

HAL is a multi-disciplinary open access archive for the deposit and dissemination of scientific research documents, whether they are published or not. The documents may come from teaching and research institutions in France or abroad, or from public or private research centers.
L'archive ouverte pluridisciplinaire HAL, est destinée au dépôt et à la diffusion de documents scientifiques de niveau recherche, publiés ou non, émanant des établissements d'enseignement et de recherche français ou étrangers, des laboratoires publics ou privés. 


\title{
White light emission from Sm-doped YAG ceramic controlled by the excitation wavelengths
}

\author{
Hanan Ali ${ }^{a}$, P. Masschelein ${ }^{b}$, S. Bruyere ${ }^{b}$, P. Pigeat ${ }^{b}$, A. Dauscher ${ }^{b}$, H. Rinnert ${ }^{b}$, D. \\ Horwat $^{\mathrm{b}}$, Mohamed Atta Khedr ${ }^{\mathrm{a}}$, Alaa E. Giba ${ }^{\mathrm{a}, \mathrm{b}^{*}}$. \\ ${ }^{a}$ National Institute of Laser Enhanced Sciences, Cairo University, Giza 12613, Egypt. \\ ${ }^{b}$ Université de Lorraine, CNRS, IJL, F-54000 Nancy, France. \\ * contact :alaadin85@niles.edu.eg
}

\begin{abstract}
This work reports, for first time, on optically-driven white light emission from samarium-doped yttrium aluminum garnet ceramic, Sm-doped YAG. Nanocrystalline Sm-doped YAG sample has been prepared via co-precipitation method then transformed to bulk ceramic by sintering process using Spark Plasma Sintering (SPS) technique. X-ray diffraction (XRD) and high resolution transmission electron microscopy (HRTEM) are used to characterize the crystal structure of the nanocrystals. The micro-grains of the obtained ceramic have been demonstrated by scanning electron microscope (SEM). Photoluminescence (PL) and cathodoluminescence (CL) spectroscopies have been performed on the ceramic sample. It is found that the PL spectral features are strongly dependent on the excitation wavelength. Remarkable PL spectral overlapping between bluish-green band and reddish-orange lines related to host defects/ impurities and Sm ions, respectively, has been obtained. In addition, controlling the relative PL spectral contributions from the host-related emission and Sm ions has been achieved by changing the excitation wavelengths. This led to manipulate the emission color coordinates as investigated by chromaticity diagram. Moreover, under certain excitation wavelengths, an intense white emission is observed with a naked eye. The origin of the white emission has been discussed in light of specific PL spectral overlapping from the host and Sm ion contributions. This work emphasizes on the role played by the host defects/impurities in the optical properties of ceramic materials that can be exploited in several lighting applications.
\end{abstract}

Keywords: White emission; Sm-doped YAG; YAG Ceramics; Cathodoluminescence; Photoluminescence. 


\section{Introduction}

Luminescent ceramic materials hold promising future, not only from their outstanding electrooptical properties, but also from their low cost. In addition, the large scale production, malleability, and high mechanical strength place ceramic materials as alternative candidate to their single crystal counterparts [1]. However the use of ceramics in optical applications is still a challenge owing to their polycrystalline nature, which leads to light scattering. Presence of grain boundaries, pores, and impurities in polycrystalline microstructures are the main sources of light scattering. In this regard, seeking high optical performance and emerging new applications of ceramic materials require progress in the improvement of the optical quality together with exploring the introduction of new dopants. Ceramic materials doped with emitting ions, rare earths (REs) or transition metals...etc, are currently investigated or under development or already used for applications in optics and electronics [2-5]. More specifically, RE-doped yttrium aluminum garnet (YAG) nanopowders and ceramics phosphors are widely used in literature/industry owing to the specific structure and optical properties of YAG as host material[6]. For instance, it contributes to a new generation of solid state lasers by helping to design laser ceramic materials with enhanced efficiency, extended emission range and high power scaling[7-9]. Among REs ions, $\mathrm{Sm}^{3+}$ was used as dopant in various solid matrices. Intense visible emission and the long lifetime from its ${ }^{4} \mathrm{G}_{5 / 2}$ excitedstate are advantageous for the field of solid state lightening[10]. Recently, the incorporation of $\mathrm{Sm}^{3+}$ in different forms of materials (glasses, single crystals, polycrystalline materials or nanocrystalline powders) has attracted a lot of attention [11-12]. However, the luminescence properties of Sm-doped YAG ceramic have not been reported so far. The characteristic reddish-orange emission from $\mathrm{Sm}$ ions combined with blue and green, or yellow emission from other ions have been proposed for white light generation approaches[13]. In this regard, $\mathrm{Sm}^{3+}$, as a red emitter, could be used to improve the color rendering index. Thus, multi-phosphors color mixing process is needed and carefully manipulated for white light generation and control. Nevertheless, optimizing the color ratios between these phosphors is a nontrivial task. Therefore thinking in a way to generate white light free from intentionally multi-phosphors color mixing to avoid the mixing problems is highly sought[14].

Therefore, this work focuses on manipulation of the emission spectra from YAG ceramic singlydoped with $\mathrm{Sm}$ ion to avoid the multi-phosphors complexity. The luminescence of the host 
defects is exploited as an additional color source along with Sm emission color. Moreover, the ratio of the color mixing is externally overcomed by controlling the excitation wavelengths. This leads to fine tuning of the emission spectra and eventually results in a white light observed with a naked eye.

\section{Experimental section}

Samarium-doped yttrium aluminum garnet has been prepared via reverse strike co-precipitation method. High purity of nitrite precursors such as; $\mathrm{Y}\left(\mathrm{NO}_{3}\right) 3 \cdot 6 \mathrm{H}_{2} \mathrm{O}, \mathrm{Al}\left(\mathrm{NO}_{3}\right)_{3} \cdot 9 \mathrm{H}_{2} \mathrm{O}$, and $\mathrm{Sm}\left(\mathrm{NO}_{3}\right)_{3} \cdot 6 \mathrm{H}_{2} \mathrm{O}$ were used. The precursors were mixed in aqueous solution to an appropriate molar ratio to obtain the stoichiometric formula, $\mathrm{Sm}_{0.06} \mathrm{Y}_{2.94} \mathrm{Al}_{5} \mathrm{O}_{12}$ that shows the best optical and crystallographic features. A $0.5 \mathrm{M}$ of ammonium hydrogen carbonate $\left(\mathrm{NH}_{4} \mathrm{HCO}_{3}\right)$ was dissolved in distilled water. The salt solution was added to the precipitant solution to induce precipitation at $\mathrm{pH}=$ 7.9. Then, it has been aged for $12 \mathrm{~h}$, filtered and washed with water and ethanol. After that, the precipitation was dried at $80^{\circ} \mathrm{C}$ for $24 \mathrm{~h}$, and then calcined at $1000^{\circ} \mathrm{C}$ for $2 \mathrm{~h}$. For ceramic fabrication, the calcined nanopowder underwent sintering process using Spark Plasma Sintering technique, SPS, (Fuji Electronic Industrial, Model 515 S). The SPS experiments were performed in vacuum using graphite dies. A suitable amount of powder was poured into the die and graphite foils (Grafoil) were used as spacers between the specimen and the graphite die and punches. Then, the graphite die was placed inside vacuum chamber and the sample pre-pressed to $80 \mathrm{MPa}$ before heating. The pressure was maintained during the heating and the whole sintering process and released during the cooling stage after the sintering was finished. A heating rate of 100 ${ }^{\circ} \mathrm{C} / \mathrm{min}$ was applied till the maximum temperature of $1150{ }^{\circ} \mathrm{C}$. The temperature was monitored using both thermocouple and optical pyrometer. Structural analysis of the nanopowder was performed using X-ray diffraction (Philips Analytical X-Ray, $0.154 \mathrm{~nm}$ for $\mathrm{CuK} \alpha$ ) and transmission electron microscopy (TEM) in a JEOL ARM 200-Cold. The morphology of the obtained ceramic sample was investigated by scanning electron microscopy (SEM). The photoluminescence (PL) measurements and the photoluminescence excitation (PLE) spectroscopy were carried out with a spectrofluorometer (Fluorolog-Horiba). A xenon arc lamp source was used for the tunable excitation and the PL emission was analyzed by a detection system equipped with a 150 grooves/mm gratings and a cooled silicon-based CCD camera. The 
$325 \mathrm{~nm}$ line of He-Cd laser was used for demonstration of the laser-driven white light emission. Cathodoluminescence (CL) measurement has been performed using an home-made setup. The CL spectra were collected after excitation with energetic electron beam (accelerating voltage 10 $\mathrm{kV}$ and filament current $10 \mathrm{nA}$ ) of $1 \mu \mathrm{m}^{2}$ scanning area.

\section{Results and discussion}

\section{1- Structure characterization}
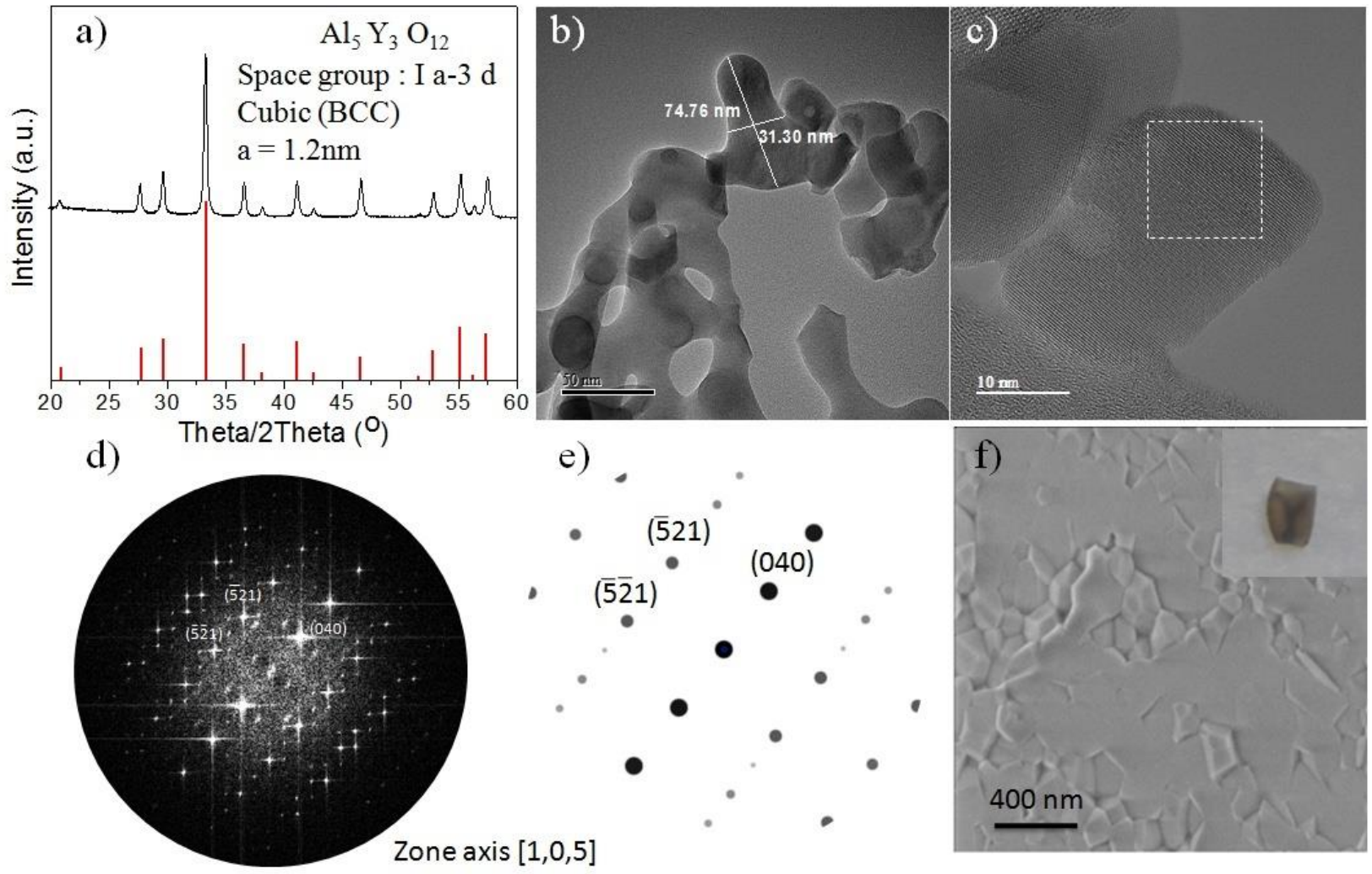

e)

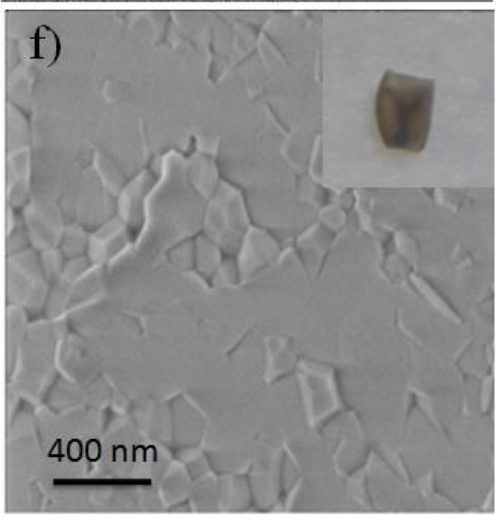

Fig. 1. (a-e) XRD, TEM , HRTEM, FFT and simulation of SAED pattern of Sm-doped YAG nanopowder; respectively. (f) Surface SEM image and photograph (inset) of Sm-doped YAG ceramic..

The XRD diffractogram of the prepared Sm-doped YAG nanopowder is shown in Fig. 1 (a). It represents the diffraction peaks belonging to the body centered cubic structure of YAG phase in agreement with COD (card No. 2003066)and confirms the absence of secondary phases. For gaining further information about the microstructure, TEM and HRTEM micrographs with the FFT (Fast Fourier Transform) pattern from the HRTEM micrographs have been performed, see 
Fig. 1 (b, c, and d). The nanoparticles are somewhat agglomerated and display irregular round morphology with an average size about30-40 $\mathrm{nm}$ for the individual particles and extending to 75 $\mathrm{nm}$ for the agglomerated ones. In addition, the HRTEM image, along with the FFT, verifies the crystal nature of the formed YAG phase, which is also confirmed with the simulation of SAED pattern done by JEM software along the $[1,0,5]$ zone axis. These findings are also in agreement with the XRD results. In order to analyze the morphology of the ceramic phase, the SEM photograph of Sm-doped YAG ceramic sample has been collected, as shown in Fig. 1 (f). It can be observed that the formed grains exhibit different shapes and orientations. This results in irregular grain boundaries and formation of many pores, which act as light scattering sources. This also explains the very low transparency of the obtained ceramic. This microstructure and the poor transparency could be well adapted for applications in the context of optical reflection. This will be evaluated in the following.

\section{2- Luminescence spectroscopy}

\subsection{Photoluminescence (PL)}

The steady state photoluminescence of Sm-doped YAG ceramic sample has been measured at different successive excitation wavelengths between $260 \mathrm{~nm}$ and $440 \mathrm{~nm}$, with a step equals to 5 $\mathrm{nm}$. It is found that the PL spectral features are strongly depending on the excitation wavelengths. Thus, for better analyzing, the PL results are presented in four groups (A, B, C, and D). Fig. 2 (a) shows the PL spectra corresponding to excitation wavelengths from $260 \mathrm{~nm}$ to $320 \mathrm{~nm}$ (group A). It can be observed that the PL spectra exhibit small narrow peaks falling in the visible region from $550 \mathrm{~nm}$ to $725 \mathrm{~nm}$ in addition to a broad PL band centered around $825 \mathrm{~nm}$. 

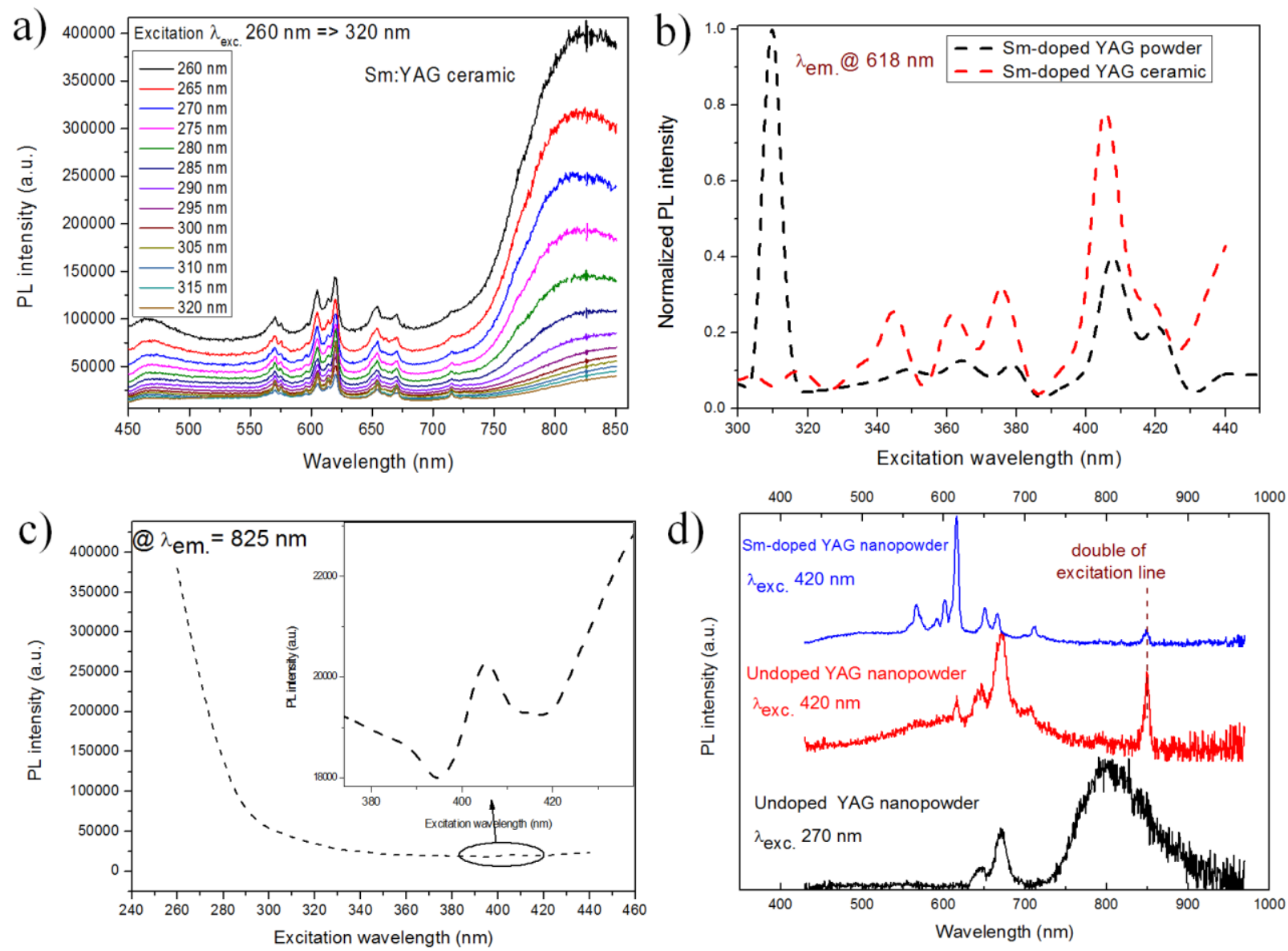

Fig. 2. a) PL spectra of Sm-doped YAG ceramic sample under different excitation wavelengths from $260 \mathrm{~nm}$ to 320 $\mathrm{nm}$. PLE spectra of Sm-doped YAG ceramic monitored at emission wavelength $618 \mathrm{~nm}$ (b) and at emission band 825 $\mathrm{nm}$ (c). Inset fig. (c). is a zoom in around $400 \mathrm{~nm}$ of the PLE. d) PL spectra of undoped YAG nanopowder, excited by $270 \mathrm{~nm}$ (black) and $420 \mathrm{~nm}$ (red), and PL spectrum of Sm-doped YAG nanopowder excited by $420 \mathrm{~nm}$ (blue).

The origin of the narrow peaks, in orange-red region, is referred to the emission lines of excited $\mathrm{Sm}^{3+}$ ions, as discussed in the reported work [15]. It has been attributed to specific intraconfigurational $4 f-4 f$ transitions of $\mathrm{Sm}^{3+}$ ions namely: ${ }^{4} \mathrm{G}_{5 / 2}-{ }^{6} \mathrm{H}_{5 / 2}$ (at $567 \mathrm{~nm}$ - yellow), ${ }^{4} \mathrm{G}_{5 / 2}-{ }^{6} \mathrm{H}_{7 / 2}$ (at $618 \mathrm{~nm}$ - orange, the most intense), ${ }^{4} \mathrm{G}_{5 / 2}{ }^{6} \mathrm{H}_{9 / 2}$ (at $652 \mathrm{~nm}$ - red), and ${ }^{4} \mathrm{G}_{5 / 2}{ }^{6} \mathrm{H}_{11 / 2}$ (at $712 \mathrm{~nm}$ the weakest one). However for confirming the origin of these lines in the present study, the PLE spectrum of Sm-doped YAG ceramic monitoring the emission peak at $618 \mathrm{~nm}$ has been measured, Fig. 2 (b).The PLE spectral features are in good agreement with those already reported from $\mathrm{Sm}^{3+}$ ions[16]. This agreement in the PLE spectra further confirms the origin of these PL peaks to the electronic transitions of $\mathrm{Sm}^{3+}$. Nevertheless, the behavior of the broad NIR-band centered at $825 \mathrm{~nm}$ was not fully explored so far. We find that the PL intensity of the broad NIR- 
band decreases relatively to the intensity of the narrow peaks as the excitation wavelength increases (from $260 \mathrm{~nm}$ to $320 \mathrm{~nm}$ ). It is worth to mention that similar broad NIR-band around $800 \mathrm{~nm}$ has been reported by C. R. Varney et al[17] in undoped YAG single crystal. They also observed, mainly from samples grown in oxidized conditions, emission band superimposed with multiple peaks in the range of $650 \mathrm{~nm}-750 \mathrm{~nm}$. The authors attributed the origin of all these emission contributions to unavoidable very low content of iron impurity. This low content of iron, $\mathrm{Fe}^{3+}$, substitutes the octahedral and/or the tetrahedral Al-sites in YAG crystal lattice and induces emission band and lines between 600-1000 nm [17-18]. In our sample, the source of the low content of $\mathrm{Fe}$ impurities has been found in the certificate of analysis of the used $\mathrm{Al}\left(\mathrm{NO}_{3}\right)_{3} .9 \mathrm{H}_{2} \mathrm{O}$ precursor. This $\mathrm{Fe}$ impurity is commonly reported in other studies [19].Based on that, different mechanisms were proposed as origin of these Fe-related emission band and lines:(i) charge transfer from oxygen $2 p$ level to $\mathrm{Fe}$ band (responsible for optical absorption at $255 \mathrm{~nm}$ ), (ii) $\mathrm{Fe}-\mathrm{Fe}$ interaction in different lattice sites, $2 \mathrm{Fe}^{3+} \rightarrow \mathrm{Fe}^{2+}+\mathrm{Fe}^{4+}$, (responsible for optical absorption at $407 \mathrm{~nm}$ and $415 \mathrm{~nm}$ ) and (iii) direct $\mathrm{Fe}^{3+}$ absorption at $400-420 \mathrm{~nm}$ due to transition of the $3 \mathrm{~d}$ valence electron[17-18]. In order to test the above hypotheses, we measured the PLE monitoring the $825 \mathrm{~nm}$ band on our ceramic sample. The PLE spectrum, Fig. 2 (c), exhibits strong band starting from $280 \mathrm{~nm}$ and extending to shorter wavelengths. In addition, a small hump in range $400 \mathrm{~nm}-420 \mathrm{~nm}$ can be observed, inset Fig. 2 (c). These results are in line with the above reported explanations about the origin of the $825 \mathrm{~nm}$ band. Moreover, the continuous decrease in intensity observed in our PLE is consistent with that observed by C. R. Varney et al[17]. However, the reported emission lines related to $\mathrm{Fe}^{3+}$ in the range of $650 \mathrm{~nm}-750$ $\mathrm{nm}$ are not observed from the present sample. For further confirming the origin of the NIR band to the iron impurities and exclude the influence of the Sm dopant, undoped YAG nanopowder has been prepared. The PL of this YAG nanopowder has been measured under UV and visible excitation by $270 \mathrm{~nm}$ and $420 \mathrm{~nm}$, respectively and compared to Sm-doped YAG nanopowder sample, Fig. 2 (d). In the undoped sample, narrow PL lines in range 600-700 $\mathrm{nm}$ are observed under both UV and visible excitations. Whereas the broad band around $800 \mathrm{~nm}$ is obtained only by UV excitation. This is in agreement with the Fe-related emission reported for undoped YAG single crystal [17]. It is worth to mention that $\mathrm{Fe}^{3+}$ shows several emission lines/bands in NIR and visible regions. These $\mathrm{Fe}^{3+}$ lines mainly originate from its $d$ - $d$ electronic transitions [18, 20-22]. This result obtained with our undoped sample, in agreement with literature, confirms that $\mathrm{Fe}$ 
impurities are at the origin of these emissions. In addition, the PL of Sm-doped YAG nanopowder, Fig. 2 (d), points to the suppression of the emission lines related to $\mathrm{Fe}^{3+}$ thanks to incorporation of $\mathrm{Sm}$ and confirms the discrimination between $\mathrm{Sm}^{3+}$ and $\mathrm{Fe}^{3+}$ related emission lines. It is worth to mention that C. R. Varney et al[17] also noticed a suppression of the $\mathrm{Fe}^{3+}$ emission lines in undoped YAG single crystal samples grown under reducing atmosphere, i.e. oxygen-deficient conditions. Hence, it can be proposed that the reason behind the suppression of the $\mathrm{Fe}^{3+}$ emission lines, in our study, is due to the formation of a reducing local environment around $\mathrm{Fe}^{3+}$ after incorporation of $\mathrm{Sm}$ ions. This also can be linked with the appearance of a weak broad PL hump around 500-530 nm in Sm-doped YAG nanopowder, Fig. 2 (d). This infers that a defect center has formed in the host after the incorporation of Sm ions. This defect center in metal oxide-based materials is likely assigned to oxygen vacancy [21-22]. The role of this host defect will be further manifested in the following discussions. Hence, it can be concluded that, the origin of the PL-band around $825 \mathrm{~nm}$ in Sm-doped YAG ceramic sample is related to the host impurity of $\mathrm{Fe}^{3+}$ and not to the presence of $\mathrm{Sm}^{3+}$ ions.

Fig. 3 (a) shows the second range of excitation wavelengths, (group B), from $325 \mathrm{~nm}$ to $355 \mathrm{~nm}$. In this range, the PL spectra show a suppression of the NIR-band. On the contrary, a significant enhancement in the narrow PL peaks related to $\mathrm{Sm}^{3+}$ transition lines can be found overlapped with appearance of a broad band located in the $500 \mathrm{~nm}-650 \mathrm{~nm}$ range. In addition, the PL intensity of this broad band exhibits a specific trend with the excitation wavelengths, as shown in inset Fig. 3 (a). The band intensity increases with the excitation wavelength from $325 \mathrm{~nm}$ to 340 $\mathrm{nm}$, where a maximum is reached and then diminishes gradually till it is completely suppressed by excitation at $355 \mathrm{~nm}$. This wavelength-dependent excitation of the band in blue/green region overlapped with the Sm-related PL lines in reddish orange region, importantly, enables to tune the emission color as observed in the CIE chromaticity diagram of this sample, Fig. 3 (b). It shows that the coordination point exhibits displacement behavior with respect to the white region and excitation wavelength. The coordinate point moves away from the white light central zone with excitations from $325 \mathrm{~nm}$ to $340 \mathrm{~nm}$, then it moves back to the white light region from excitation by $345 \mathrm{~nm}$ to $355 \mathrm{~nm}$. Hence, this indicates a correlation between the coordination points with the behavior of the intensity of the emission of the blue/green band, as shown before in inset of Fig. 3 (a). This also infers that the blue/green emission band controls the appearance of the emission color. In addition, table 1 shows all the emission coordinates (x, y), CCT and CRI 
of Sm-doped YAG ceramic sample at different excitation wavelengths of group B. The emission coordinates (x, y) of excitation wavelengths $325 \mathrm{~nm}$ and $355 \mathrm{~nm}$ reveal very close values to the theoretical white emission coordinate point $(0.33,0.33)$. This indicates white emission could be achieved at the excitation wavelengths $325 \mathrm{~nm}$ and $355 \mathrm{~nm}$, corresponding to a color temperature of $4255 \mathrm{~K}$ and $4021 \mathrm{~K}$, respectively, i.e. in the so-called cool white range. This can be verified by strong eye-observed white light emission upon exciting the sample by $325 \mathrm{~nm}$ line of $\mathrm{He}-\mathrm{Cd}$ laser and, left inset photo of Fig. 3 (d). This white light can be attributed to the combination between the blue/green band with the reddish orange emission lines related to $\mathrm{Sm}^{3+}$ ions.
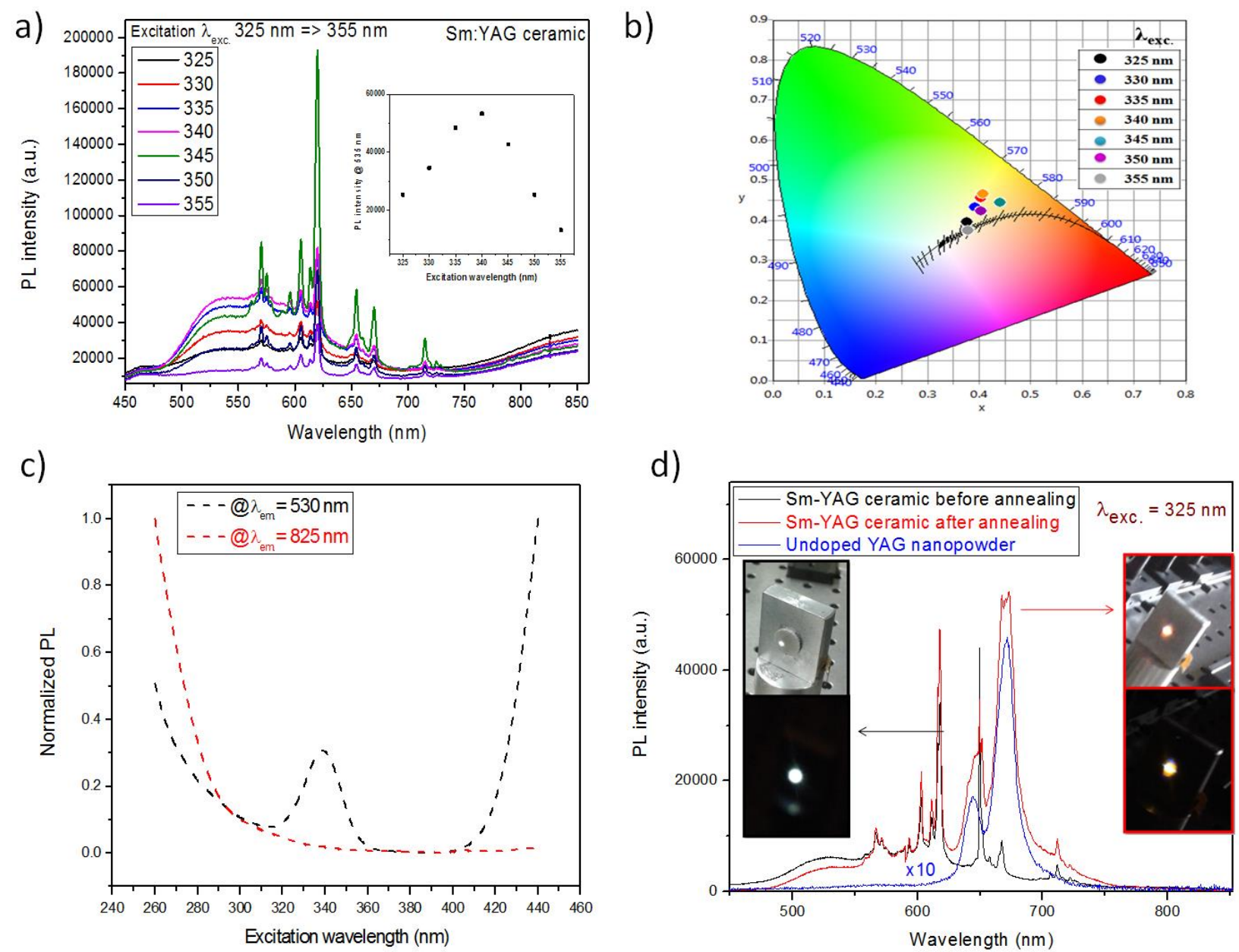

Fig. 3. a) PL spectra of Sm-doped YAG ceramic sample under excitation of wavelengths from $325 \mathrm{~nm}$ to $355 \mathrm{~nm}$, Inset fig. (a) the PL intensity of the band at $535 \mathrm{~nm}$ as a function of this excitation wavelengths. b) CIE chromaticity diagram of Sm-doped YAG ceramic sample as a function of excitation wavelengths from $325 \mathrm{~nm}$ to $355 \mathrm{~nm}$. c) PLE spectra of Sm-doped YAG ceramic sample monitored at $530 \mathrm{~nm}$ and $825 \mathrm{~nm}$ emission bands. d) PL spectra excited by $325 \mathrm{~nm}$ of Sm-doped ceramic sample before and after annealing and undoped YAG nanopowder. Inset photos are 
the observed white emission color from Sm-doped ceramic sample before (left) and after annealing (right) under excitation by $325 \mathrm{~nm}$ line of He-Cd laser in light and dark backgrounds.

Table 1. The CIE 1931 coordinate (X and Y), color temperature (CCT) and color rendering index (CRI) of the PL of Sm-doped YAG ceramic sample under different excitation wavelengths.

\begin{tabular}{rcccc}
\hline $\boldsymbol{\lambda}_{\text {exc. }}$ & $\mathbf{X}$ & $\mathbf{Y}$ & $\mathbf{C C T}(\mathbf{K})$ & $\mathbf{C R I}$ \\
$325 \mathrm{~nm}$ & 0.3757 & 0.3962 & 4255 & 89 \\
$330 \mathrm{~nm}$ & 0.3914 & 0.4326 & 4089 & 81 \\
$335 \mathrm{~nm}$ & 0.4042 & 0.4566 & 3960 & 77 \\
$340 \mathrm{~nm}$ & 0.4074 & 0.4654 & 3946 & 75 \\
$345 \mathrm{~nm}$ & 0.4401 & 0.4433 & 3244 & 84 \\
$350 \mathrm{~nm}$ & 0.4043 & 0.4235 & 3763 & 86 \\
$355 \mathrm{~nm}$ & 0.3788 & 0.3735 & 4021 & 96 \\
\hline
\end{tabular}

However, the origin of the broad band in the blue/green region is still an open question. Referring to literature, undoped YAG crystal likely exhibits defect related emission spectra with wealth of bands and sub-bands [23]. These bands, as discussed above, are mostly attributed to impurities (e.g. $\left.\mathrm{Fe}^{3+}\right),\left(\mathrm{F}^{+}, \mathrm{F}, \mathrm{F}^{-}\right.$-centers) or $\mathrm{O}^{-}$center [24-30]. The defect emission from $\mathrm{Fe}-\mathrm{Fe}$ impurity is responsible for absorption bands at 407 and $415 \mathrm{~nm}$. In addition, $\mathrm{F}^{+}, \mathrm{F}, \mathrm{F}^{-}$- centers in YAG were ascribed to oxygen vacancies filled with trapped electrons (single, double and triple electrons; respectively). $\mathrm{O}^{-}$center was described as converting $\mathrm{O}^{2-}$ ion into $\mathrm{O}^{-}$by releasing an electron under UV excitation at $\sim 240 \mathrm{~nm}$. This released electron either recombines again in the same center to retrieve $\mathrm{O}^{2-}$ or transfers to a vicinity impurity $\left(\mathrm{Fe}^{3+}\right.$ or $\mathrm{RE}$ ion) or oxygen vacancy to form F-centers. To gain more information on the origin of this broad band in our sample, whose maximum is at $530 \mathrm{~nm}$, PLE measurement has been performed by monitoring the $530 \mathrm{~nm}$ maximum and was compared to the PLE recorded for $825 \mathrm{~nm}$ emission band, as shown in Fig. 3 (c). The PLE shows three predominant contributions to the excitation of the $530 \mathrm{~nm}$ emission, while only one main band beside two weak bands, as discussed above, are found in the PLE related to $825 \mathrm{~nm}$ emission. This indicates that different excitation path ways are involved in the 
excitation of the two broad bands. The PLE contribution of lower wavelengths is found for both emission bands. The two other PLE features, peaked at $340 \mathrm{~nm}$ and rising from $420 \mathrm{~nm}$, are exclusive to the $530 \mathrm{~nm}$ emission band. The latter PLE bands can be referred to excitation of one of the F-centers, oxygen vacancy filled with electron(s), as reported elsewhere [25-29]. However, the role of the $\mathrm{O}^{-}$center cannot be excluded since it is considered as a source of electron that can be involved in oxygen-Fe interaction and/or forming F-centers. For better understanding the origin of this band, it is noticed that the existence of a weak emission band, in the same range, around $500 \mathrm{~nm}$, is associated to incorporation of Sm in YAG nanopowder and accompanied with suppression of the narrow lines related to $\mathrm{Fe}^{3+}$, Fig. 2 (d). This can point to a possible interaction between the origin of this band and $\mathrm{Fe}^{3+}$. In addition, we proposed, see discussion on Fig. 2 (d), a link between the local deficiency of oxygen and appearance of Fe-emission lines. In order to verify this link, Sm-doped YAG ceramic sample has been underwent annealing in oxidizing condition, $950{ }^{\circ} \mathrm{C} / 5 \mathrm{hrs}$ in air. The PL spectra of the Sm-YAG ceramic before and after annealing are shown in Fig. 3 (d). In Sm-YAG ceramic sample after annealing in oxidizing conditions, it can be observed a significant appearance of the $\mathrm{Fe}^{3+}$ emission lines accompanied with a decrease in this blue/green emission band with respect to the ceramic sample before annealing. This confirms the favorable oxidizing conditions for $\mathrm{Fe}^{3+}$ emission lines and evidences its link with the band around $530 \mathrm{~nm}$. In addition, the PL spectrum of undoped YAG nanopowder excited at $325 \mathrm{~nm}$ also contains the $\mathrm{Fe}^{3+}$ emission lines, evidencing the link of the existence of the band with incorporation of $\mathrm{Sm}$ in YAG at $325 \mathrm{~nm}$. Moreover, this spectral modification due to annealing in oxidizing conditions leads to generate an orange halo around the eye observed white emission spot, right inset photo of Fig. 3 (d). This further confirms the importance of the spectral ratio between the blue/green band and the reddish orange emission lines. Therefore, it can be concluded that the emission band around $530 \mathrm{~nm}$ is originating from mutual interaction between oxygen-related defect (e.g. oxygen vacancy likely due to $\mathrm{Sm}$ incorporation) and $\mathrm{Fe}^{3+}$ ions.

These findings confirm the important role played by the YAG defects in its emission spectrum that can be exploited, as in our case, to generate white light emission from Sm-doped YAG. This approach demonstrates the possibility of producing white light from intentionally single-doped phosphor, Sm-doped YAG ceramic, without using several phosphors. Moreover, it indicates that the white emission is composed from specific mixing ratios between blue/green, and red components that can be controlled and tuned by the excitation wavelengths. To the best of our 
knowledge, this is the first report on white light emission from single-doped YAG ceramic with $\mathrm{Sm}$. In most reported work about the generation of white light, $\mathrm{Sm}^{3+}$ is used as red emission activator beside doping of other blue/green and/or yellow activator(s) ions [31-32].

In contrast, the PL spectra of the third range of excitation wavelengths (group C) from $360 \mathrm{~nm}$ to $410 \mathrm{~nm}$ exhibit predominance of the emission lines related to the electronic transitions of $\mathrm{Sm}^{3+}$, Fig. 4.

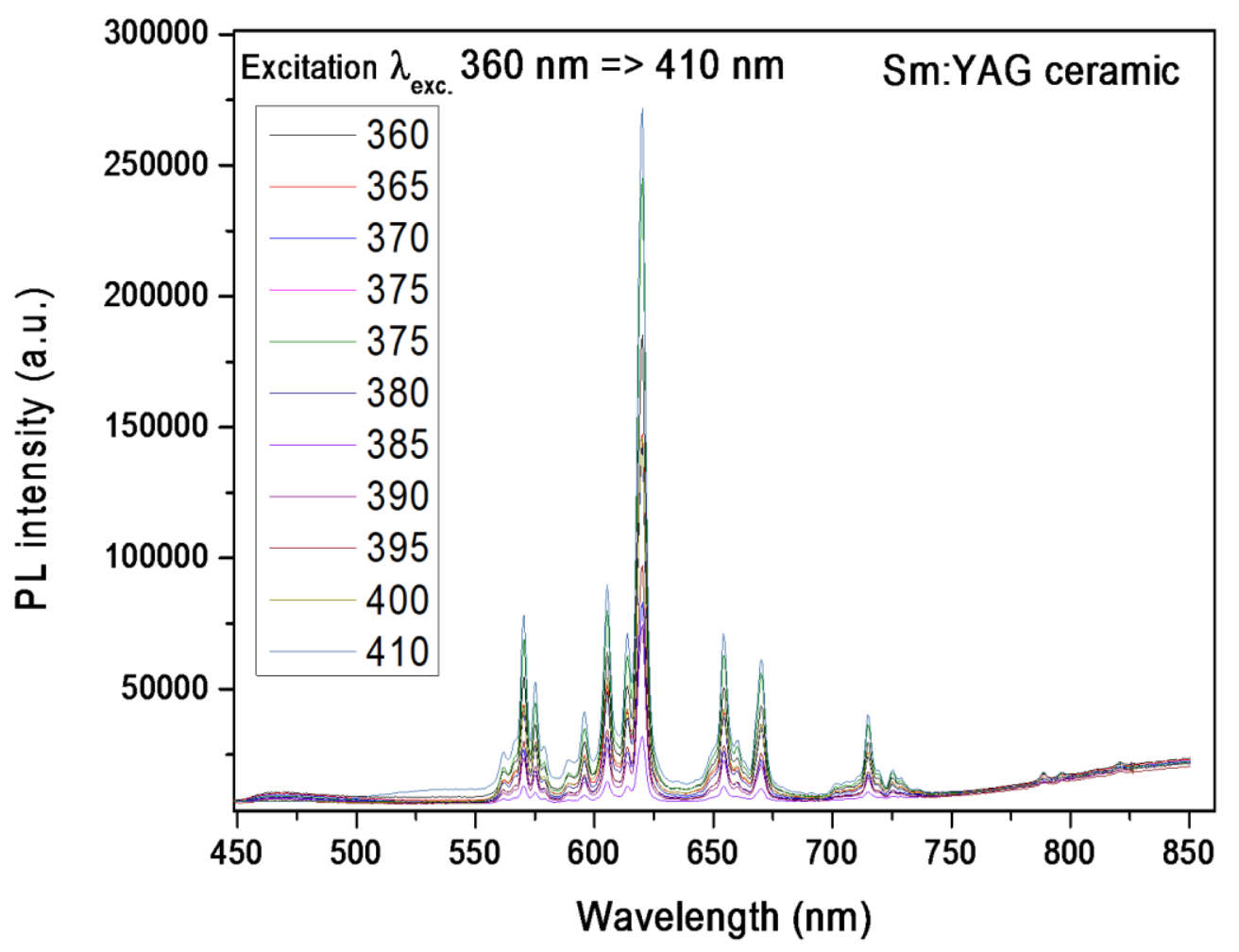

Fig. 4. PL spectra of Sm-doped YAG ceramic sample under excitation of wavelength from $360 \mathrm{~nm}$ to $410 \mathrm{~nm}$.

The blue/green and NIR emission bands are dramatically suppressed. This can be expected from the PLE data presented in Fig. 3 (c), that shows the absence of the excitation features of these two emission bands in the PLE rangefrom $360 \mathrm{~nm}$ to $410 \mathrm{~nm}$. The assignment of these emission lines of $\mathrm{Sm}^{3+}$ ions has been mentioned above.

Collected PL spectra for the last range of excitation wavelengths (group D) from $415 \mathrm{~nm}$ to 440 nm, are shown in Fig. 5 (a).The blue/green emission band re-appears again with strong contribution and it overlaps with all $\mathrm{Sm}^{3+}$ emission lines. This strong contribution is also expected 
from the PLE monitored at this band, in Fig. 3 (c), as a strong increase in the PLE spectrum beyond $400 \mathrm{~nm}$ was observed.
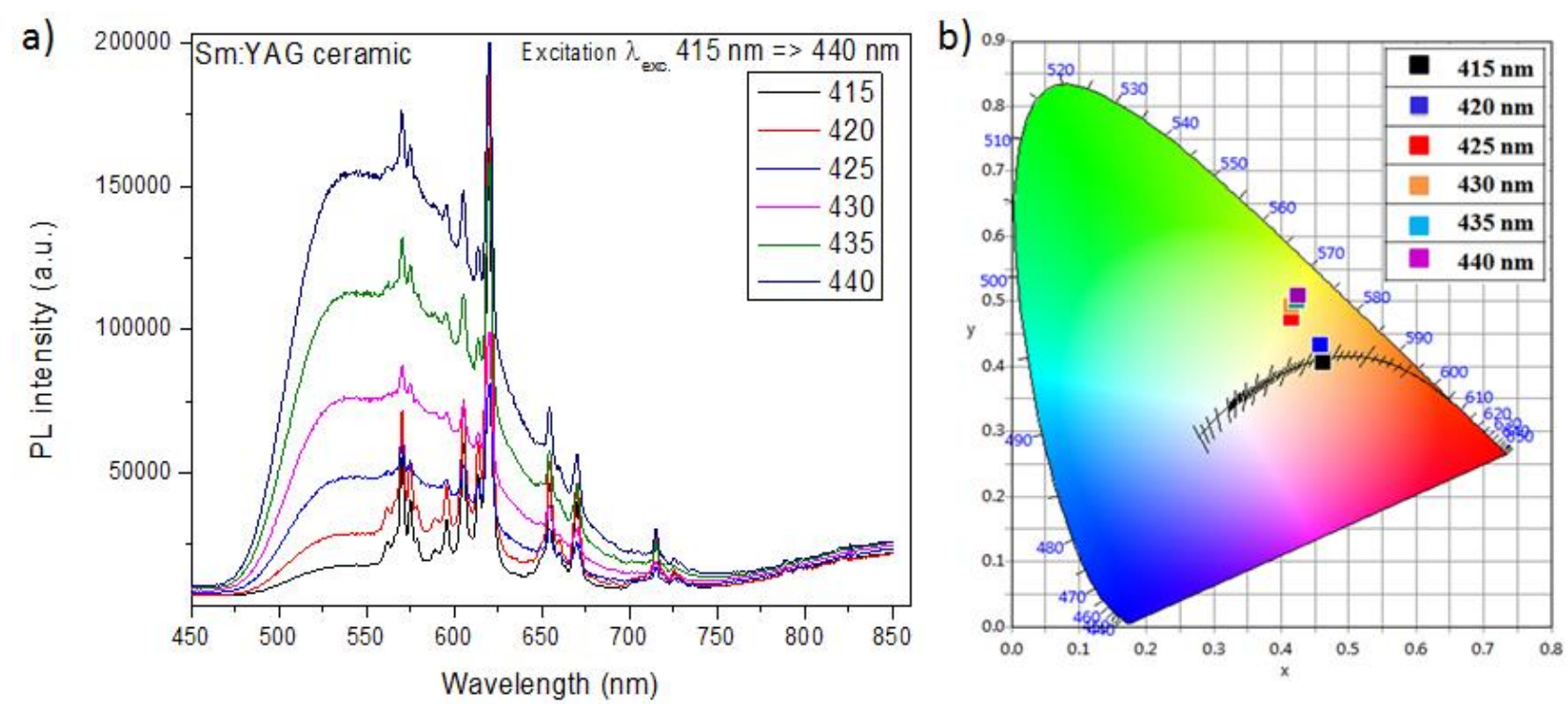

Fig. 5. a) PL spectra and (b) CIE chromaticity diagram of Sm-doped YAG ceramic sample as a function of excitation wavelengths from $415 \mathrm{~nm}$ to $440 \mathrm{~nm}$.

In addition, the CIE diagram, Fig. 5 (b), shows a modification in the emission color with the excitation wavelengths. The combination between the blue/green band and orange/red lines of $\mathrm{Sm}^{3+}$ leads to move the emission color from orange to yellow according to the excitation wavelength. Despite the strong contribution of the blue/green band within this group D compared to group B, it doesn't lead to white emission. The intensity of this blue/green band relative to orange-red emission lines need to be optimized to obtain the white emission. These findings show how the excitation wavelength can be exploited to optimize the ratio of the color components. Thus, a suitable UV or blue excitation source can be chosen to obtain the desired emission color. This approach is in line with the proposed strategy of white light generation in phosphor-based LED (pc-LED) that contains UV-LED exciting yellow or multicolor phosphors [33-34]. It also offers great opportunity to manipulate the required emission color by accurately tuning the excitation wavelength. In this direction, it is worth to mention that white light emitting diodes devices suffer from a serious technological issue. Due to the significant decrease of the external quantum efficiency of the LED at high excitation power, realizing white LED devices based on high power excitation regime is difficult [35]. Alternatively, high power laser diode can be 
achieved without exhibiting the efficiency droop phenomenon observed in LEDs. This opens the door for using blue or UV-laser diode, instead of LEDs, in some applications requiring high power sources. For instance, laser diodes have been used as excitation sources in white light production process [36-38]. In this case, blue or UV-laser diode is used in a remote configuration to pump a yellow or mixture of red-, green-, and blue-emitting phosphors that lead to white light [36-38]. This laser-driven white light process is characterized by high luminescence efficiency and small heat generation around the emitting phosphors as well as small spot size of white emission that can be guided easily by optical fiber for specific applications. However, laserpumped white light generation requires different optical arrangements than LED based applications. Owing to the directionality and the high intensity of the laser, a reflection optical configuration setup is more adapted. This is usually realized by combination of the phosphor plate and reflectors or the use of phosphor-coated integrating sphere, as described in [3940]. These unique properties of laser-driven white light approach was recently exploited by BMW company to develop new car's headlamps with high luminescence and long range of visibility compared to the headlamps based on LEDs [41]. In laser-based headlamps, a blue laser diode is used to pump a yellow-emitting phosphor via optical fiber. Such remote phosphor configuration will further reduce the overheating problem of producing white light excitable by blue or UV in single LED [42].

\subsection{Cathodoluminescence $(\mathrm{CL})$}

Apart from the optically-pumped applications, cathodoluminescence is a non-incandescent emission of light when electrons are used as the mean of excitation. In this case, the incident energetic electrons excite the phosphor, which can be subsequently followed by the emission of photons. It is worth to mention that materials which exhibit CL response can be considered as potential candidates in applications such as field-emission displays [43-44]. Thus, CL measurement has been performed on Sm-doped YAG ceramic sample. Fig. 6 shows the CL spectrum which consists of the four emission characteristic peaks of Sm ions, as described above. Hence, the direct observation of Sm-YAG ceramic exposed to the electron beam in CL experiment gives an orange-red light well visible with the naked eye. This result indicates that 
our developed ceramic sample is also promising for application requiring the injection of electrons, like in field-emission displays.

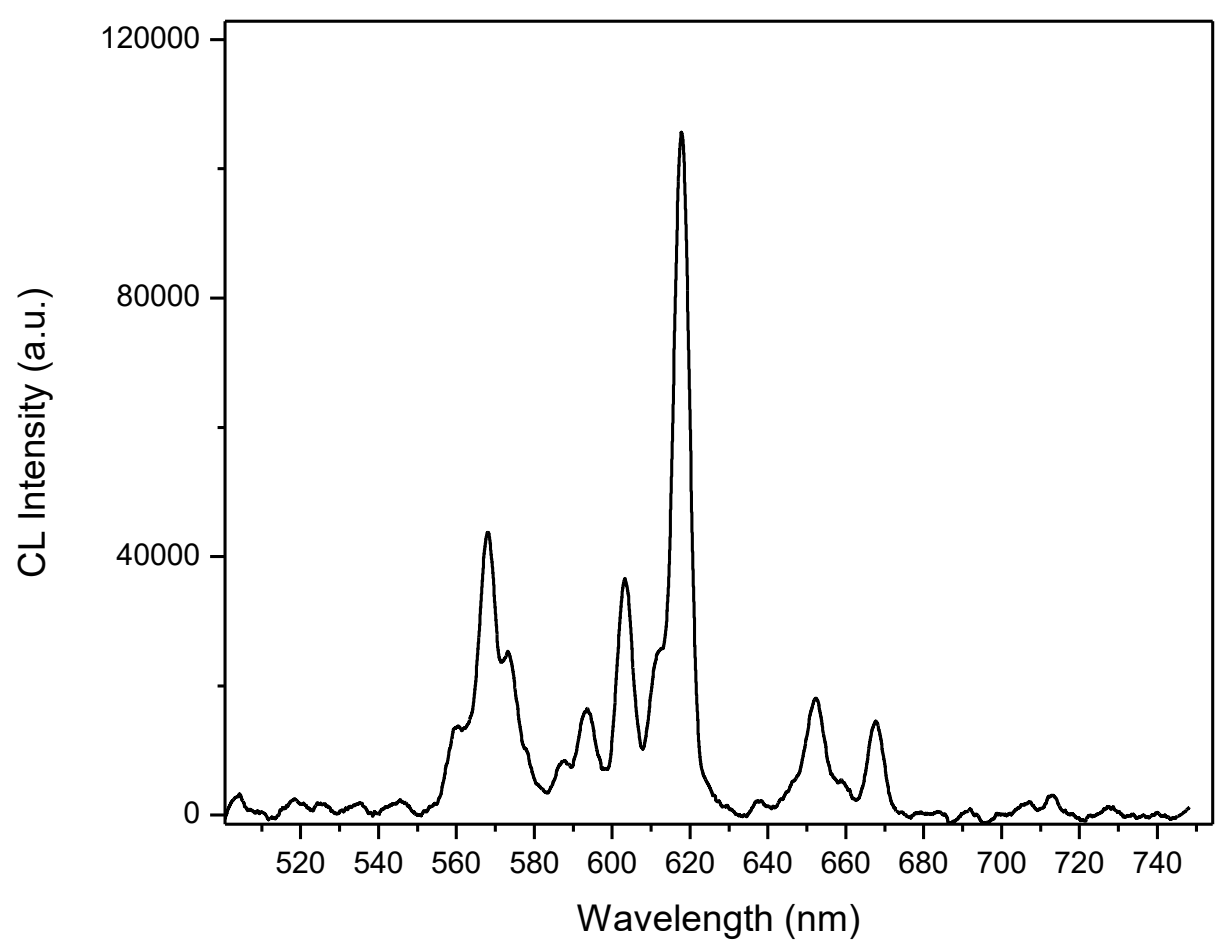

Fig. 6. Cathodoluminescence spectrum of Sm-doped YAG ceramic.

\section{Conclusion}

Nanocrystalline and ceramic samples of Sm-doped YAG have been prepared by co-precipitation method. The structure analyses using XRD and HRTEM exhibited a pure YAG phase. Detailed PL results showed a strong dependence of the optical emission with the excitation wavelengths. The PL spectra exhibit PL contributions from host impurities, defects and $\mathrm{Sm}^{3+}$ transition bands and lines. Based on the PL and PLE measurements in comparison with undoped sample, the origin of the host-related emissions was attributed to intrinsic Fe impurity and mutual interaction between $\mathrm{Fe}$ and oxygen related defects, in agreement with reported works. The relative PL contributions between the host defects and $\mathrm{Sm}^{3+}$ ions have been controlled by the excitation wavelengths; resulting in manipulation of the color coordinates of the emission spectra as 
evidenced by chromaticity diagrams. Laser-induced white light emission has been obtained under an excitation at $325 \mathrm{~nm}$. The origin of the observed naked-eye white emission was referred to specific PL spectral combination from the host defect/impurity and $\mathrm{Sm}^{3+}$ ions. In addition, the role of the host defects in controlling the color quality was discussed. Moreover, CL measurement on ceramic sample showed the possibility of using the prepared ceramic sample in field-emission displays applications. These findings highlight a promising strategy based on the excitation wavelength-dependent approach in lightening applications.

\section{References}

[1] P. Boch, J.C. Nièpce, Ceramic Materials: Processes, Properties, and Applications, Wiley2010.

[2] A. Majid, N. Rani, M. Malik, N. Ahmad, H. Najam al, F. Hussain, A. Shakoor, A review on transition metal doped silicon carbide, Ceram. Inter. 45 (2019).

[3] R. Yuan, M. Huang, F. Zheng, Q.-L. Li, Z. Xu, J.-F. Hu, J. Zou, W. Yang, Z.-J. Zhang, J.-T. Zhao, Rapid, convenient and low-energy preparation of spherical rare earth doped YAG phosphors by a laser sintering method, J. Mater. Chem. C 7 (2019) 13070-13079.

[4] S. Sameshima, T. Ichikawa, M. Kawaminami, Y. Hirata, Thermal and mechanical properties of rare earth-doped ceria ceramics, Mater. Chem. Phys. 61 (1999) 31-35.

[5] D.L. Chubb, A.T. Pal, M.O. Patton, P.P. Jenkins, Rare earth doped high temperature ceramic selective emitters, J. Eur. Ceram Soc. 19 (1999) 2551-2562.

[6] S. Kostić, Z.Ž. Lazarević, V. Radojević, A. Milutinović, M. Romčević, N.Ž. Romčević, A. Valčić, Study of structural and optical properties of YAG and Nd:YAG single crystals, Mater. Res. Bull. 63 (2015) 80-87.

[7] A. Ikesue, Y.L. Aung, Ceramic laser materials, Nature Photonics 2 (2008) 721.

[8] J. Sanghera, W. Kim, G. Villalobos, B. Shaw, C. Baker, J. Frantz, B. Sadowski, I. Aggarwal, Ceramic laser materials: Past and present, Opt. Mater. 35 (2013) 693-699.

[9] Y. Rabinovitch, D. Tétard, M.D. Faucher, M. Pham-Thi, Transparent polycrystalline neodymium doped YAG: synthesis parameters, laser efficiency, Opt. Mater. 24 (2003) 345-351.

[10] P.K. Naktode, K.N. Shinde, N.S. Kokode, Effective red-orange emitting CaMgPO4Cl:Sm3+ halophosphate phosphor, Results Phys. 6 (2016) 869-872.

[11] A. Strzęp, W. Ryba-Romanowski, R. Lisiecki, X. Xu, J. Xu, J. Di, Spectroscopic characterization of CaNb2O6 single crystal doped with samarium ions, J. Lumin. 151 (2014) 123-129.

[12] S. Lange, I. Sildos, M. Hartmanova, J. Aarik, V. Kiisk, Luminescence properties of Sm3+-doped polycrystalline ZrO2, J. Non-Cryst. Solids 354 (2008) 4380-4382.

[13] P. Van Do, V.X. Quang, L.D. Thanh, V.P. Tuyen, N.X. Ca, V.X. Hoa, H. Van Tuyen, Energy transfer and white light emission of KGdF4 polycrystalline co-doped with Tb3+/Sm3+ ions, Opt. Mater. 92 (2019) 174180.

[14] A.E. Giba, P. Pigeat, S. Bruyere, H. Rinnert, F. Soldera, F. Mücklich, D. Horwat, From Blue to White Luminescence in Cerium-Doped Aluminum Oxynitride: Electronic Structure and Local Chemistry Perspectives, J. Phys. Chem. C 122 (2018) 21623-21631.

[15] S.B. Stevens, C.A. Morrison, M.D. Seltzer, M.E. Hills, J.B. Gruber, Emission measurements and crystal-field calculations for 4G5/2 to 6H7/2 transitions in Sm3+:YAG, J. Appl. Phys. 70 (1991) 948-953. 
[16] H.N. Baig, J.K. Saluja, D. Harnath, A.S.S. Prasad, K.V.R. Murthy, Preparation and Photoluminescence of Sm 3+ Doped YAIO 3 Phosphor, J. Fluoresc. 26 (2016) 757-768.

[17] C.R. Varney, S.M. Reda, D.T. Mackay, M.C. Rowe, F.A. Selim, Strong visible and near infrared luminescence in undoped YAG single crystals, AIP Adv. 1 (2011) 042170.

[18] S.R. Rotman, C. Warde, H.L. Tuller, J. Haggerty, Defect-property correlations in garnet crystals. V. Energy transfer in luminescent yttrium aluminum-yttrium iron garnet solid solutions, J. Appl. Phys. 66 (1989) 3207-3210.

[19] M. Mączka, A. Bednarkiewicz, E. Mendoza-Mendoza, A.F. Fuentes, L. Kępiński, Low-temperature synthesis, phonon and luminescence properties of Eu doped Y3Al5O12 (YAG) nanopowders, Mater. Chem. Phys. 143 (2014) 1039-1047.

[20] K. Kniec, M. Tikhomirov, B. Pozniak, K. Ledwa, L. Marciniak, LiAl(5)O(8):Fe(3+) and LiAl(5)O(8):Fe(3+), $\mathrm{Nd}(3+)$ as a New Luminescent Nanothermometer Operating in 1st Biological Optical Window, Nanomaterials (Basel) 10 (2020) 189.

[21] P.B. Devaraja, D.N. Avadhani, H. Nagabhushana, S.C. Prashantha, S.C. Sharma, B.M. Nagabhushana, H.P. Nagaswarupa, B.D. Prasad, Luminescence properties of MgO: Fe3+ nanopowders for WLEDs under NUV excitation prepared via propellant combustion route, J. Radiat. Res. Appl. Sci. 8 (2015) 362-373. [22] H.B. Premkumar, H. Nagabhushana, S.C. Sharma, B. Daruka Prasad, B.M. Nagabhushana, J.L. Rao, R.P.S. Chakradhar, Synthesis, EPR and luminescent properties of YAIO3:Fe3+ (0.1-0.9mol\%) nanopowders, Spectrochim. Acta A 126 (2014) 220-226.

[23] L. Zhang, J. Wu, P. Stepanov, M. Haseman, T. Zhou, D. Winarski, P. Saadatkia, S. Agarwal, F.A. Selim, H. Yang, Q. Zhang, Y. Wang, C. Wong, H. Chen, Defects and solarization in YAG transparent ceramics, Photon. Res. 7 (2019) 549-557.

[24] A. Pujats, M. Springis, The F-type centres in YAG crystals, Radiat. Eff. Defect. Solids 155 (2001) 65-69. [25] J. Kvapil, J. Kvapil, B. Perner, O- centre formation in YAG crystals doped with rare earth ions, Kristall und Technik 10 (1975) 161-165.

[26] K. Mori, Transient colour centres caused by UV light irradiation in yttrium aluminium garnet crystals, phys. status solidi a 42 (1977) 375-384.

[27] J. Kvapil, J. Kvapil, J. Kubelka, V. Kubeček, Transient absorption and laser output of YAG : Nd, Czech. J. Phys. B 31 (1981) 644-651.

[28] K. čermák, Optical polaron absorption in YAG: Nd, Czech. J. Phys. B 31 (1981) 1172-1176.

[29] G. Phillipps, J. Vater, 1.06- $\mu \mathrm{m}$ absorption caused by stable color centers in flash-lamp-pumped Nd:YAG laser rods, Appl. Opt. 32 (1993) 3210-3216.

[30] H. Bernhardt, Formation of biparticles in nominally undoped Y3Al5O12 crystals?, phys. status solidi a 31 (1975) 365-370.

[31] R. Shi, J. Xu, G. Liu, X. Zhang, W. Zhou, F. Pan, Y. Huang, Y. Tao, H. Liang, Spectroscopy and Luminescence Dynamics of Ce3+ and Sm3+ in LiYSiO4, J. Phys. Chem. C 120 (2016) 4529-4537.

[32] W.U. Khan, L. Zhou, Q. Liang, X. Li, J. Yan, N.U.R. Rahman, L. Dolgov, S.U. Khan, J. Shi, M. Wu, Luminescence enhancement and energy transfers of $\mathrm{Ce} 3+$ and $\mathrm{Sm} 3+$ in $\mathrm{CaSrSiO} 4$ phosphor, J. Mater. Chem. C 6 (2018) 7612-7618.

[33] J.S. Kim, P.E. Jeon, Y.H. Park, J.C. Choi, H.L. Park, G.C. Kim, T.W. Kim, White-light generation through ultraviolet-emitting diode and white-emitting phosphor, Appl. Phys. Lett. 85 (2004) 3696-3698.

[34] M. Worku, L.-J. Xu, M. Chaaban, A. Ben-Akacha, B. Ma, Optically pumped white light-emitting diodes based on metal halide perovskites and perovskite-related materials, APL Mater. 8 (2020) 010902.

[35] J. Cho, E.F. Schubert, J.K. Kim, Efficiency droop in light-emitting diodes: Challenges and countermeasures, Laser Photonics Rev. 7 (2013) 408-421.

[36] Y. Xu, L. Chen, Y. Li, G. Song, Y. Wang, W. Zhuang, Z. Long, Phosphor-conversion white light using InGaN ultraviolet laser diode, Appl. Phys. Lett. 92 (2008) 021129. 
[37] Y. Xu, H. Hu, W. Zhuang, G. Song, Y. Li, L. Chen, White light emission from ultraviolet laser diode, LaPhy 19 (2009) 403-406.

[38] H.-Y. Ryu, D.-H. Kim, High-brightness Phosphor-conversion White Light Source Using InGaN Blue Laser Diode, J. Opt. Soc. Korea 14 (2010) 415-419.

[39] A.F. George, S. Al-waisawy, J.T. Wright, W.M. Jadwisienczak, F. Rahman, Laser-driven phosphorconverted white light source for solid-state illumination, Appl. Opt. 55 (2016) 1899-1905.

[40] K.A. Denault, M. Cantore, S. Nakamura, S.P. DenBaars, R. Seshadri, Efficient and stable laser-driven white lighting, AIP Adv. 3 (2013) 072107.

[41] C. Basu, M. Meinhardt-Wollweber, B. Roth, Lighting with laser diodes, Advanced Optical Technologies, 2013, p. 313.

[42] Y.H. Song, E.K. Ji, B.W. Jeong, M.K. Jung, E.Y. Kim, D.H. Yoon, High power laser-driven ceramic phosphor plate for outstanding efficient white light conversion in application of automotive lighting, Sci. Rep. 6 (2016) 31206.

[43] P. Du, J.S. Yu, Photoluminescence, cathodoluminescence and thermal stability of Sm3+-activated Sr3La(VO4)3 red-emitting phosphors, Luminescence 32 (2017) 1504-1510.

[44] Z. Liu, M. Stevens-Kalceff, H. Riesen, Photoluminescence and Cathodoluminescence Properties of Nanocrystalline BaFCl:Sm3+ X-ray Storage Phosphor, J. Phys. Chem. C 116 (2012) 8322-8331. 